\title{
Three Years after Legalization of Nonprescription Pharmacy Syringe Sales in California: Where Are We Now?
}

Richard S. Garfein, Thomas J. Stopka, Patricia B. Pavlinac, Alessandra Ross, B. Karen Haye, Elise D. Riley, and Ricky N. Bluthenthal

\begin{abstract}
In January 2005, passage of California Senate Bill 1159 enabled California's county or city governments to establish disease prevention demonstration projects (DPDPs) through which pharmacies could subsequently register to legally sell up to 10 syringes to adults without a prescription. California's 61 local health jurisdictions (LHJs) were surveyed annually in 2005-2007 to monitor the progress of DPDP implementation and assess program coverage, facilitators, and barriers. Completed surveys were returned by mail, fax, e-mail, phone, or internet. We analyzed 2007 survey data to describe current DPDP status; data from all years were analyzed for trends in approval and implementation status. By 2007, 17 (27.9\%) LHJs approved DPDPs, of which $14(82.4 \%)$ had registered $532(17.8 \%)$ of the 2,987 pharmacies in these 14 LHJs. Although only three LHJs added DPDPs since 2006, the number of registered pharmacies increased 102\% from 263 previously reported. Among the LHJs without approved DPDPs in 2007, one (2.3\%) was in the approval process, seven (16.3\%) planned to seek approval, and $35(81.4 \%)$ reported no plans to seek approval. Of 35 LHJs not planning to seek approval, the top four reasons were: limited health department time $(40 \%)$ or interest $(34 \%)$, pharmacy disinterest $(31 \%)$, and law enforcement opposition (26\%). Among eight LHJs pursuing approval, the main barriers were "time management" (13\%), educating stakeholders (13\%), and enlisting pharmacy participation (13\%). The 17 LHJs with DPDP represent $52 \%$ of California's residents; they included $62 \%$ of persons living with HIV and $59 \%$ of IDU-related HIV cases, suggesting that many LHJs with significant numbers of HIV cases have approved DPDPs. Outcome studies are needed to determine whether SB 1159 had the desired impact on increasing syringe access and reducing blood-borne viral infection risk among California IDUs.
\end{abstract}

KEYWORDS Injection drug use, Harm reduction, Syringe access, HIV, Hepatitis C virus, Health policy

Garfein, Pavlinac, and Haye are with the Department of Medicine, Division of Global Public Health, School of Medicine, University of California, San Diego, CA, USA; Stopka and Ross are with the Office of AIDS, Center for Infectious Diseases, California Department of Public Health, Sacramento, CA, USA; Riley is with the Department of Medicine, University of California, San Francisco, CA, USA; Bluthenthal is with the Urban Community Research Center, Sociology Department, California State University Dominguez Hills, Santa Monica, CA, USA, and the Health Program and Drug Policy Research Center, RAND Corporation, Santa Monica, CA, USA; Haye is with the Department of Pediatrics, University of California San Diego, San Diego, CA, USA.

Correspondence: Richard S. Garfein, PhD, MPH, Division of Global Public Health, Department of Medicine, University of California San Diego, 9500 Gilman Drive, mailstop 0507, San Diego, CA 92093-0507, USA. (E-mail: rgarfein@ucsd.edu)

Source of Support This study was funded by the Office of AIDS (OA), Center for Infectious Diseases, California Department of Public Health (CDPH) (grant \#06-55589). 


\section{INTRODUCTION}

Injection drug use is the second leading cause of HIV and the leading cause of hepatitis $\mathrm{C}$ virus (HCV) infection in California. ${ }^{1}$ According to California HIV/AIDS surveillance data, injection drug use accounts for $10.4 \%$ of all newly reported AIDS cases and $19.1 \%$ of cases when male injection drug users (IDUs) who also report having sex with men are included. ${ }^{2}$ Similarly, injection drug use is the primary risk factor for HCV infection, likely accounting for more than $60 \%$ of prevalent cases and most incident cases in the USA. ${ }^{3}$ An estimated 600,000 Californians, or $2 \%$ of the state's population, are infected with $\mathrm{HCV}$, of which 475,000 Californians are currently living with chronic hepatitis C in California. ${ }^{4}$ In San Francisco, $45 \%$ of IDUs under 30 years of age have HCV antibody, ${ }^{5}$ and among IDUs who injected longer than 6 years, $71 \%$ are anti-HCV positive. ${ }^{6}$ Young IDUs in San Francisco are at high risk for HCV infection with an annual incidence of $26.7 \% .^{7}$ Transmission of these and other blood-borne infections occurs through sharing syringes and other injection paraphernalia that are contaminated with HCV or HIV-infected blood. ${ }^{8,9}$

While cessation of injection drug use is the ideal prevention strategy, this is not always achievable, and studies indicate that making sterile syringes readily available to IDUs decreases the prevalence of blood-borne viral infections ${ }^{10,11}$; thus, the US Public Health Service recommends one-time use of sterile syringes for IDUs who continue to inject. ${ }^{12}$ Other studies found lower HIV infection rates and risky injection practices among IDUs in US cities without laws requiring a prescription compared to cities with prescription laws. ${ }^{11,13}$ Efforts to increase syringe access include syringe exchange programs (SEPs); however, reported barriers to accessing SEPs include fear of being labeled as an IDU, police harassment, inadequate syringe supply, limited operating hours, limited privacy, and long travel distance. ${ }^{14}$ Nonprescription syringe sales (NPSS) provide an important adjunct to SEPs as a source of sterile syringes. ${ }^{15}$

Senate Bill 1159 (SB 1159) (Chapter 608, Statutes of 2004) ${ }^{16}$ was signed into legislation and enacted on January 1, 2005. According to the legislation, "The Disease Prevention Demonstration Project (DPDP) is authorized for the purpose of evaluating the long-term desirability of allowing licensed pharmacists to furnish or sell nonprescription hypodermic needles or syringes to prevent the spread of bloodborne pathogens, including HIV and hepatitis C." Participation in the program is voluntary, and a two-step "opt-in" process was required before syringes can be legally sold without a prescription. The first step permits local health jurisdictions (LHJs) to establish DPDPs after approval by a local governing body. The second step requires pharmacies in LHJs with a DPDP to register with the local health department (LHD) before they may legally sell $\leq 10$ syringes to customers $\geq 18$ years old without a prescription. California's two-step “opt-in” process offers a unique contrast to other states that have legalized NPSS on a statewide basis, without requiring additional local approval.

SB 1159 also decriminalized possession of $\leq 10$ syringes obtained from an authorized source such as a pharmacy. Under the DPDP, registered pharmacies must provide customers a mechanism for safe disposal of used syringes and information about HIV prevention and drug treatment. LHDs must maintain lists of registered pharmacies and provide pharmacies with printed educational materials for their customers. Without new legislation, SB 1159 provisions will sunset on December 31, 2010. 
To monitor the approval and implementation status of DPDPs statewide, we surveyed California LHJs annually between 2005 and 2007. California is divided in to 61 LHJs served by 58 county and three city health departments (Pasadena, Berkeley, and Long Beach). Results from the 2005 survey were published previously. ${ }^{17}$ Data from the past three surveys were used to describe the current state of the DPDPs 3 years after SB 1159 passed and to elucidate trends in DPDP approval and implementation.

\section{METHODS}

Between 2005 and 2007, three annual surveys were conducted among health departments in California's 61 LHJs. Questionnaires were initially sent to health officers in each LHJ and support garnered during meetings of the California Conference of Local Health Officers, the California Conference of Local AIDS Directors, and the County Health Executives Association of California. Alternate respondents were requested when someone other than the health officer was primarily responsible for DPDP activities. Questionnaires also requested contact information for the person who would be most appropriate for future surveys. Through this process, we were able to identify individuals most knowledgeable about SB 1159.

Methods for the 2006 and 2007 surveys were similar to the 2005 survey, reported elsewhere. ${ }^{17}$ Surveys were mailed and e-mailed to health officials with CA Office of AIDS endorsement. An online survey option was added in 2007. Nonresponders received reminder letters followed by phone calls when needed to assure high response rates. Responses could be returned by mail, fax, e-mail, internet, or telephone.

The questionnaire was developed in consultation with an advisory board founded in 2004 and comprised of state and local public health officials, academic researchers, pharmacists, law enforcement, waste management representatives, and IDU advocates. Questionnaire topics included DPDP approval and implementation status, program characteristics, facilitators, and barriers to approval and implementation, pharmacy registration status, syringe disposal, and technical assistance needs. We used 2007 data to describe the current status of SB 1159, while data from all 3 years were used to describe trends in approval and implementation of DPDPs over time. To assess whether DPDPs were approved in communities needing HIV prevention, we compared DPDP coverage to 2007 California population estimates (California Department of Finance) ${ }^{18}$ and cumulative HIV statistics. ${ }^{2}$

\section{RESULTS}

Overall, 57 (93.4\%) LHJs responded in 2005, 55 (90.2\%) responded in 2006, and $60(98.4 \%)$ responded in 2007. One LHJ (City of Pasadena) did not respond in 2007 but participated in Los Angeles County's DPDP. Respondents in 2007 consisted of health department staff $(33 \%)$, health officers and deputy health officers $(30 \%)$, public health executives $(15 \%)$, HIV/AIDS program coordinators/ directors $(12 \%)$, and public health nurses $(10 \%)$.

By December 2007, DPDPs were approved in 17 (27.9\%) LHJs, reflecting an $89 \%$ increase from 2005 and a 21\% increase from 2006 (Table 1). The number of LHJs in the process of seeking local government approval for a DPDP declined in 2007 compared to 2006 and 2005 (one, two, and eight LHJs, respectively). 
TABLE 1 Disease Prevention Demonstration Project (DPDP) status by year among California's 61 local health jurisdictions

\begin{tabular}{lccr}
\hline DPDP status & 2005 & 2006 & 2007 \\
\hline Approved & 9 & 14 & 17 \\
In process of approving & 8 & 2 & 1 \\
Plan to approve & 17 & 9 & 7 \\
Approval process on hold & 2 & 0 & 0 \\
No plans to approve & 18 & 25 & 35 \\
Status unknown & 3 & 5 & 0 \\
Survey not completed & 4 & 6 & 1 \\
\hline
\end{tabular}

Additionally, the number of LHJs planning, though not actively proceeding, to approve a DPDP also declined in 2007 compared to 2006 and 2005 (seven, nine, and 17 LHJs, respectively). Given that the number of LHJs without plans to approve a DPDP increased in 2007 compared to 2006 and 2005 (35, 25, and 18 LHJs, respectively), it appears that by 2007, most LHJs considering DPDPs had either already received local government approval or abandoned plans to do so. Examining pharmacy registration by year revealed that by 2007, 14 (82\%) of the 17 approved DPDPs had registered pharmacies into the program; however, the proportion of pharmacies that were registered within each LHJ varied from $0 \%$ to $61 \%$ (Table 2). Of note, the Santa Cruz County Board of Supervisors approved a DPDP in 2005 for cities within the unincorporated areas of the county, but the cities were held responsible by the county for also authorizing the program. As of 2007, no pharmacies had been registered.

A comparison of survey data to California Population and HIV Case Reporting data revealed that approximately $52 \%$ of California's population resided in the 17 LHJs with DPDPs (Table 3). These LHJs included $62 \%$ of reported persons living with HIV and $59 \%$ of IDU-related HIV cases. LHJs with no plans to approve a DPDP represent approximately $43 \%$ of California's population, $32 \%$ of reported persons living with HIV, and 35\% of IDU-related HIV cases. Although California's most populous LHJ (Los Angeles) has a DPDP, the next four most populous LHJs (Orange, Riverside, San Diego, and San Bernardino Counties), including over 10 million residents, do not.

Of the 35 LHJs without plans to approve DPDPs in 2007, 40\% cited "competing priorities-limited time" as a reason for not approving a DPDP. Additionally, "competing priorities-limited interest" (34\%), "lack of pharmacy interest" $(31 \%)$, and "law enforcement opposition" $(26 \%)$ were other major reasons for not approving DPDPs. The greatest implementation challenges for the 17 LHJs with DPDPs were: "time management" (24\%), "enlisting pharmacy participation" (24\%), and "securing DPDP approval" (24\%). Similarly, the eight LHJs planning or in the process of approving a DPDP cited "time management" $(13 \%)$; "educating stakeholders" such as police, pharmacists, policy makers, and community members $(13 \%)$; and "enlisting pharmacy participation" $(13 \%)$ as barriers to approval.

Syringe disposal costs and SEP presence were also examined because these factors may be considered by governing boards deciding on DPDP approval. In 2007 , respondents estimated that DPDP costs for syringe disposal ranged from $\$ 0$ to $\$ 850$ per month. Costs were reportedly absorbed by "integration into existing waste 
TABLE 2 Pharmacies registered by year among 17 local health jurisdictions with approved Disease Prevention Demonstration Projects

\begin{tabular}{|c|c|c|c|c|}
\hline \multirow[b]{2}{*}{ LHJ } & \multirow[b]{2}{*}{ Approval date } & \multicolumn{3}{|c|}{$N(\%)^{\mathrm{a}}$ pharmacies registered } \\
\hline & & 2005 & 2006 & 2007 \\
\hline Contra Costa & Dec. 2004 & $32(22)$ & $62(43)$ & $64(42)$ \\
\hline Yuba & Jan. 2005 & $3(38)$ & $3(38)$ & $3(38)$ \\
\hline Marin & Mar. 2005 & $12(35)$ & $13(37)$ & $14(41)$ \\
\hline Alameda/Berkeley ${ }^{b}$ & Mar. 2005 & 41 (19) & $75(34)$ & $66 / 6(33)$ \\
\hline Santa Cruz & Mar. 2005 & - & - & $0(0)$ \\
\hline San Francisco & Apr. 2005 & $35(26)$ & $64(49)$ & $71(55)$ \\
\hline Yolo & May 2005 & $10(42)$ & $19(76)$ & $17(61)$ \\
\hline Los Angeles (city) & Jun. 2005 & - & - & $183(11)$ \\
\hline Santa Barbara & Sept. 2005 & - & - & $23(38)$ \\
\hline Solano & Sept. 2005 & - & $15(29)$ & $15(29)$ \\
\hline Humboldt & Oct. 2005 & - & - & $0(0)$ \\
\hline San Mateo & Dec. 2005 & - & - & $0(0)$ \\
\hline Santa Clara & Jan. 2006 & - & $6(2)$ & $53(21)$ \\
\hline San Luis Obispo & Mar. 2006 & - & - & $1(2)$ \\
\hline Sonoma & Sept. 2006 & - & $6(9)$ & $6(9)$ \\
\hline Sacramento (city) & Dec. 2006 & - & - & $10(5)$ \\
\hline Total & & $133(23.6)$ & $263(28.2)$ & $532(17.8)$ \\
\hline
\end{tabular}

${ }^{\text {a }}$ Percentages were calculated by dividing the number of registered pharmacies by the number of commercial, non-clinic-based, pharmacies licensed by the California Board of Pharmacy in the county during the year of the survey

${ }^{\mathrm{b}}$ Alameda and Berkeley are classified as independent LHJs, but total pharmacy data are aggregated between the two

management" (29\%), “subsidization by local health department" (21\%), and "surcharges added to syringe price" $(7 \%) ; 21 \%$ reported that "syringe disposal posed no additional cost." As of July 2007, California had 39 SEPs operating in 17 LHJs, ${ }^{19} 13(76.5 \%)$ of which overlapped with the 17 LHJs with DPDPs versus five $(11.6 \%)$ SEPs in the $43 \mathrm{LHJs}$ surveyed without a DPDP.

Evaluating technical assistance needs and coalition status across all 60 LHJs in 2007 revealed that only $15(25 \%)$ received technical assistance for SB 1159 during the previous year from: OA $(80 \%)$, peers in other LHJs $(53 \%)$, website developed by $\mathrm{OA}^{20}(40 \%)$, and other sources $(20 \%)$. Eight $(47 \%)$ of the 17 LHJs with a DPDP had established coalitions to assist with DPDP approval and implementation, while only five $(11.6 \%)$ out of 44 LHJs without DPDPs formed coalitions.

\section{DISCUSSION}

Annual surveys conducted during the first 3 years since SB 1159 passage revealed that by December 2007, only 17 of California's 61 LHJs had approved DPDPs, in which less than one fifth of the pharmacies had registered to sell nonprescription syringes. Most DPDPs were authorized shortly after SB 1159 passed and few additional LHJs still considered implementing DPDPs 3 years after passage. While only a quarter of the California's LHJs approved DPDPs, over 52\% of the state's population and $62 \%$ of persons living with HIV were represented in this pilot, giving credence to the generalizability of findings from additional studies assessing 
TABLE 3 Disease Prevention Demonstration Project authorization status by population, reported living HIV cases and reported living cases attributed to IDU exposure among California's 61 local health jurisdictions as of December, 2007

\begin{tabular}{|c|c|c|c|c|c|c|}
\hline & \multicolumn{2}{|c|}{ California population } & \multicolumn{2}{|c|}{ Living with HIV } & \multicolumn{2}{|c|}{$\begin{array}{l}\text { HIV cases attributed to IDU } \\
\text { exposure }\end{array}$} \\
\hline & $N$ & $(\%)$ & $N$ & (\%) & $N$ & (\%) \\
\hline Authorized already & $19,680,200$ & $(51.7)$ & 15,160 & $(62.0)$ & 2,099 & $(59.4)$ \\
\hline $\begin{array}{l}\text { In process of obtain- } \\
\text { ing approval }\end{array}$ & 492,642 & $(1.3)$ & 1,163 & $(4.8)$ & 142 & $(4.0)$ \\
\hline $\begin{array}{l}\text { Not in process but } \\
\text { plan to }\end{array}$ & $1,388,209$ & (3.6) & 228 & $(0.9)$ & 47 & $(1.3)$ \\
\hline $\begin{array}{l}\text { No plans to obtain } \\
\text { approval }\end{array}$ & $16,340,285$ & $(42.9)$ & 7,846 & $(32.1)$ & 1,239 & $(35.0)$ \\
\hline $\begin{array}{l}\text { Did not complete } \\
\text { survey }\end{array}$ & 148,126 & $(0.4)$ & 69 & $(0.3)$ & 8 & $(0.2)$ \\
\hline Total & $38,049,462$ & $(100)$ & 24,466 & $(100)$ & 3,535 & $(100)$ \\
\hline
\end{tabular}

Source: California Department of Public Health, Office of AIDS, HIV/AIDS Case Registry Section; and State of California, Department of Finance

the impact of SB 1159. Since lack of time, resources, and interest were reported by several health departments as reasons for not approving DPDPs, future legislation void of the two-step "opt-in" process required during the pilot might permit a greater number of pharmacies statewide to sell syringes without a prescription as a way to reduce the risk of HIV and HCV transmission among IDUs.

Local governing bodies, informed by their health officials, may be better suited than the state government to understand the need for NPSS depending on factors such as prevalence of injection drug use or HIV infection, availability of alternate interventions, and public approval. Hence, SB 1159 allowed LHJs autonomy to decide whether or not NPSS would best serve the needs of individual communities within the country's most populous state. As the only state in the USA that requires local government approval before pharmacists can sell nonprescription syringes, California provides unique insights into NPSS legislation. Results from this study suggest that while the opt-in process allowed some LHJs to exercise their authority to keep NPSS illegal, some LHJs may have opted out simply because they lacked the time or resources to pursue the approval process. In addition, anecdotal reports from health officials indicated that that the opt-in process led to program inconsistency across LHJs, making it difficult for health departments to help one another to implement the law and avoid redundancy. This same pattern of inconsistent implementation was observed for SEP implementation in California; a process that also required local governing bodies to opt into approving SEPs. ${ }^{21}$

It is too early to determine the impact of NPSS on pharmacies and consumers in the 14 LHJs with registered pharmacies. However, Cooper and colleagues ${ }^{22}$ found through a survey of pharmacists in San Francisco and Los Angeles Counties that there have been few problems related to NPSS and that pharmacists were more likely to sell syringes without a prescription if they considered it an important HIV prevention intervention. There is also evidence from other states that NPSS decreases syringe sharing and acquisition from unsafe sources. ${ }^{23-26}$ Conversely, despite having pharmacies registered to sell nonprescription syringes, pharmacists' beliefs and 
attitudes may hinder IDUs from actually purchasing them as one study found pharmacists unwilling to sell syringes to certain customers discriminating by race or other factors. ${ }^{27}$ In other studies, pharmacists opinion's toward syringe sale varied according to their perceptions of whether NPSS prevents HIV or increases drug use, and their concerns about how selling syringes to IDUs will affect their business and the community. ${ }^{28-30}$ Riley and colleagues ${ }^{31}$ found that 2 years after legalizing NPSS in San Francisco, pharmacies effectively augmented SEPs as a source of clean syringes for IDUs. However, it is unknown whether IDUs at highest risk for bloodborne infections are aware of the law or are able to afford syringes from pharmacies. Among IDUs enrolled in a treatment facility in New York where NPSS was legalized in 2001 , less than $50 \%$ of the sample was aware that they could obtain syringes from pharmacies and even fewer actually did so. ${ }^{32}$ Additional pharmacy and consumer-level assessments of SB 1159 are needed to determine the impact of the DPDPs in California. Since SB 1159 required an evaluation without a provision for state funding, such research will depend on alternate state or federal funding.

In 2005, strong community opposition, competing priorities, law enforcement opposition, and little or no interest among pharmacies were identified as the major barriers to SB 1159 approval. ${ }^{17}$ In 2007, the most commonly reported barriers were limited time or interest due to competing priorities, suggesting some overlap with the earlier study, but perhaps also some decrease in opposition. Personal conversations and open-ended responses to the survey revealed a common emphasis by health officials on the lack of time and resources to develop DPDPs. Of note, LHJs with SEPs were more likely to approve the DPDP. Future public health legislation should consider the need for balance between allowing LHJs autonomy to implement locally suitable policy and overburdening LHJs with an approval process that could preclude only the most committed communities from adopting it.

This study was limited by potential differences in response quality across LHJs. Despite the use of a structured questionnaire and thorough follow-up of respondents in all but one LHJ, respondents' attention to their answers may vary depending on whether IDU health issues were significant concerns in the respondent's LHJ. Another limitation was that we only assessed knowledge possessed by health department officials or staff and not IDUs, pharmacists, or community members. In 2007, an online survey option was added to mailed, faxed, and telephone surveys. Although this method was believed to make responding easier for some health officials, leading to the highest response rate of the 3 years, we found no evidence that the online-survey option introduced bias. Further studies are needed to evaluate the impact of SB 1159 on these groups.

NPSS is intended to increase IDUs' access to sterile syringes and subsequently decrease their need to share syringes contaminated with HIV, HCV, or other bloodborne pathogens.

SB 1159 made it legal for California counties and cities to decide individually whether or not to remove restrictions on NPSS. This process was similar to California's legalization of SEPs and provides an important contrast to other states that legalized syringe sale or exchange on a statewide basis. ${ }^{21}$ While SB 1159 gave localities the choice of legalizing these programs, consequences of this approach include preventing the willing pharmacies in non-approved LHJs from selling syringes, complicating technical assistance to LHJs because DPDPs lack uniformity and possible confusion among consumers about where they can and cannot legally purchase syringes. While SB 1159 permitted some LHJs to implement NPSS, a measured response was observed that appears to be due to a mixture of willingness 


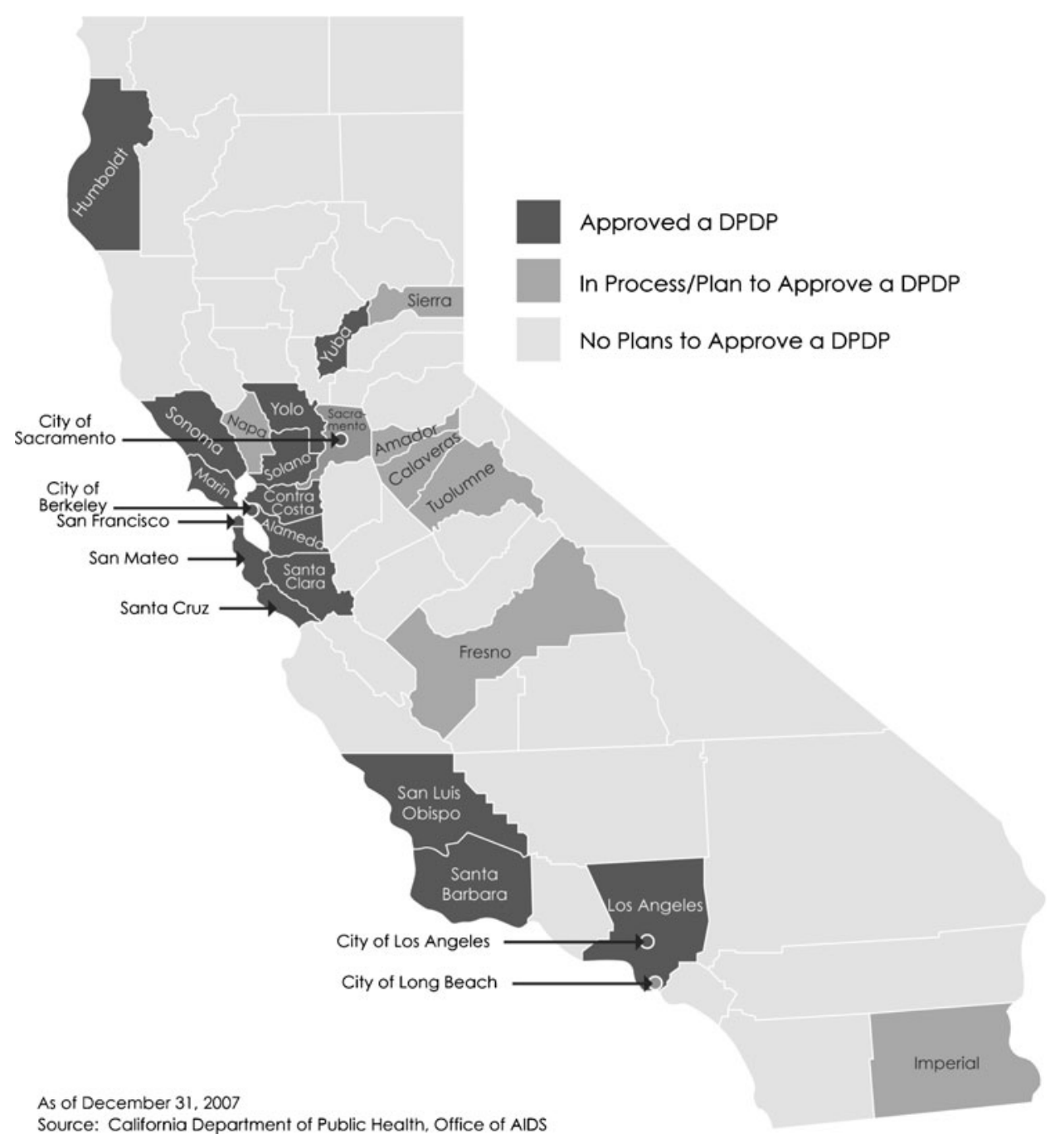

FIGURE 1. Approval status for disease prevention demonstration projects (DPDP) allowing nonprescription syringe sales by local health jurisdiction in California.

and resources across the state's 61 LHJs. Further research is needed to identify what conditions, if any, would have made it possible for additional jurisdictions to legalize nonprescription syringe sales in California.

\section{ACKNOWLEDGMENTS}

The authors gratefully acknowledge the financial contributions from CDPH/OA. We also wish to express our gratitude to the health officials throughout California who provided responses for their jurisdictions; Juan Ruiz, Mark Damesyn, and Janie Shelton from CDPH; and Glenn Backes, Valerie Rose, and Alex Kral from the SB1159 Advisory Board who were instrumental in guiding this research. John Keasling, CDPH/OA is recognized for producing Figure 1.

Disclosures. No relationships to disclose. 
OPEN ACCESS This article is distributed under the terms of the Creative Commons Attribution Noncommercial License which permits any noncommercial use, distribution, and reproduction in any medium, provided the original author(s) and source are credited.

\section{REFERENCES}

1. California Department of Public Health, Office of AIDS Fact Sheet; Injection drug users and their sex/needle-sharing partners, September 2007. Accessed on December 1, 2009. Available at: http://www.cdph.ca.gov/programs/aids/Documents/FS2527IDU2007-09-17.pdf.

2. California Department of Public Health, Office of AIDS, HIV/AIDS Case Registry Section. California HIV Injection Drug Use Exposure Cumulative Cases as of January 31, 2008. Accessed on December 1, 2009. Available at: http://www.cdph.ca.gov/data/ statistics/Documents/OA-2008-01HIVAIDSMerged.pdf.

3. Williams I. Epidemiology of hepatitis C in the United States. Am J Med. 1999; 107(6B): 2S-9S.

4. Armstrong GL, Wasley A, Simard EP, McQuillan GM, Kuhnert WL, Alter MJ. The prevalence of hepatitis C virus infection in the United States, 1999 through 2002. Ann Intern Med. 2006; 144(10): 705-714.

5. Hahn JA, Page-Shafer K, Lum PJ, Ochoa K, Moss AR. Hepatitis C virus infection and needle exchange use among young injection drug users in San Francisco. Hepatology. 2001; 34(1): 180-187.

6. Tseng FC, O'Brien TR, Zhang M, et al. Seroprevalence of hepatitis $\mathrm{C}$ virus and hepatitis B virus among San Francisco injection drug users, 1998 to 2000. Hepatology. 2007; 46 (3): 666-671.

7. Page K, Hahn JA, Evans J, et al. Acute hepatitis $\mathrm{C}$ virus infection in young adult injection drug users: a prospective study of incident infection, resolution, and reinfection. J Infect Dis. 2009; 200(8): 1216-1226.

8. Hagan H, Thiede H, Weiss NS, Hopkins SG, Duchin JS, Alexander ER. Sharing of drug preparation equipment as a risk factor for hepatitis C. Am J Public Health. 2001; 91(1): 42-46.

9. Des Jarlais DC, Semaan S. HIV prevention for injecting drug users: the first 25 years and counting. Psychosom Med. 2008; 70(5): 606-611.

10. Vlahov D, Junge B. The role of needle exchange programs in HIV prevention. Public Health Rep. 1998; 113(Suppl 1): 75-80.

11. Neaigus A, Zhao M, Gyarmathy VA, Cisek L, Friedman SR, Baxter RC. Greater drug injecting risk for HIV, HBV, and HCV infection in a city where syringe exchange and pharmacy syringe distribution are illegal. J Urban Health. 2008; 85(3): 309-322.

12. US Public Health Service, HIV prevention bulletin: medical advice for persons who inject illicit drugs (1997). Accessed on December 1, 2009. Available at: http://www.cdc.gov/idu/ pubs/hiv_prev.htm.

13. Holmberg SD. The estimated prevalence and incidence of HIV in 96 large US metropolitan areas. Am J Public Health. 1996; 86(5): 642-654.

14. Fuller CM, Galea S, Caceres W, Blaney S, Sisco S, Vlahov D. Multilevel community-based intervention to increase access to sterile syringes among injection drug users through pharmacy sales in New York City. Am J Public Health. 2007; 97(1): 117-124.

15. Pouget ER, Deren S, Fuller CM, et al. Receptive syringe sharing among injection drug users in Harlem and the Bronx during the New York State Expanded Syringe Access Demonstration Program. J Acquir Immune Defic Syndr. 2005; 39(4): 471-477.

16. Legislative Counsel. State of California. Official California Legislative Information. Accessed on December 1, 2009. Available at: http://www.leginfo.ca.gov.

17. Stopka TJ, Garfein RS, Ross A, Truax SR. Increasing syringe access and HIV prevention in California: findings from a survey of local health jurisdiction key personnel. J Urban Health. 2007; 84(1): 116-125. 
18. State of California, Department of Finance, E-1 Population Estimates for Cities, Counties and the State with Annual Percent Change - January 1, 2007 and 2008. Sacramento, California, May 2008. Accessed on December 1, 2009. Available at: http://www.dof.ca. gov/research/demographic/reports/estimates/e-1_2006-07/.

19. Ross, Alessandra (May 27, 2007) Injection Drug Use Policy and Programs Coordinator, CDPH. Interview. Quoted in The Center for Health Improvement, Policy Brief, August, 2007. Accessed on December 1, 2009. Available at: http://www.chipolicy.org/pdf/6037. Syringe\%20Policy\%20Brief.pdf.

20. Center for Health Improvement. Accessed on December 1, 2009. Available at: www. chipolicy.org.

21. Bluthenthal RN, Heinzerling KG, Anderson R, Flynn NM, Kral AH. Approval of syringe exchange programs in California: results from a local approach to HIV prevention. Am J Public Health. 2008; 98(2): 278-283.

22. Cooper E, Dodson C, Stopka TJ, Riley ED, Garfein RS, Bluthenthal RN. Pharmacy participation in non-prescription syringe sales in Los Angeles and San Francisco Counties, 2007. J Urban Health. 2010 (this issue).

23. Cotten-Oldenburg NU, Carr P, DeBoer JM, Collison EK, Novotny G. Impact of pharmacy-based syringe access on injection practices among injecting drug users in Minnesota, 1998 to 1999. J Acquir Immune Defic Syndr. 2001; 27(2): 183-192.

24. Rich JD, Hogan JW, Wolf F, et al. Lower syringe sharing and re-use after syringe legalization in Rhode Island. Drug Alcohol Depend. 2007; 89(2-3): 292-297.

25. Wodak A, Cooney A. Do needle syringe programs reduce HIV infection among injecting drug users: a comprehensive review of the international evidence. Subst Use Misuse. 2006; 41(6-7): 777-813.

26. Friedman SR, Perlis T, Des Jarlais DC. Laws prohibiting over-the-counter syringe sales to injection drug users: relations to population density, HIV prevalence, and HIV incidence. Am J Public Health. 2001; 91(5): 791-793.

27. Compton WM 3rd, Cottler LB, Decker SH, Mager D, Stringfellow R. Legal needle buying in St. Louis. Am J Public Health. 1992; 82(4): 595-596.

28. Lewis BA, Koester SK, Bush TW. Pharmacists' attitudes and concerns regarding syringe sales to injection drug users in Denver, Colorado. J Am Pharm Assoc (Wash). 2002; 42 (6 Suppl 2): S46-S51.

29. Taussig J, Junge B, Burris S, Jones TS, Sterk CE. Individual and structural influences shaping pharmacists' decisions to sell syringes to injection drug users in Atlanta, Georgia. J Am Pharm Assoc (Wash). 2002; 42 (6 Suppl 2): S40-S45.

30. Coffin PO, Linas BP, Factor SH, Vlahov D. New York City pharmacists' attitudes toward sale of needles/syringes to injection drug users before implementation of law expanding syringe access. J Urban Health. 2000; 77(4): 781-793.

31. Riley ED, Kral A, Stopka TJ, Garfein RS, Reuckhaus P, Bluthenthal RN. Access to sterile syringes through San Francisco pharmacies and the association with HIV risk behavior among injection drug users. J Urban Health. 2010 (this issue).

32. McNeely J, Arnsten JH, Gourevitch MN. Sterile syringe access and disposal among injection drug users newly enrolled in methadone maintenance treatment: a crosssectional survey. Harm Reduct J. 2006; 3: 8. 